FIGO consensus guidelines on placenta accreta spectrum disorders: Nonconservative surgical management

\title{
Allen, Lisa
}

2018

Allen , L , Jauniaux , E , Hobson , S , Papillon-Smith , J , Belfort , M A , FIGO Placenta Accreta Diagnosis and Management Expert Consensus Panel \& Tikkanen, M 2018 , ' FIGO consensus guidelines on placenta accreta spectrum disorders: Nonconservative surgical management ' , International Journal of Gynecology \& Obstetrics , vol. 140 , no. 3 , pp. 281-290 . https://doi.org/10.1002/ijgo.12409

http://hdl.handle.net/10138/312518

https://doi.org/10.1002/ijgo.12409

publishedVersion

Downloaded from Helda, University of Helsinki institutional repository.

This is an electronic reprint of the original article.

This reprint may differ from the original in pagination and typographic detail.

Please cite the original version. 


\title{
FIGO consensus guidelines on placenta accreta spectrum disorders: Nonconservative surgical management ${ }^{i s, \star}$
}

\author{
Lisa Allen $^{1}$ | Eric Jauniaux ${ }^{2, *}$ | Sebastian Hobson ${ }^{1}$ | Jessica Papillon-Smith ${ }^{1}$ | \\ Michael A. Belfort ${ }^{3}$ | for the FIGO Placenta Accreta Diagnosis and Management \\ Expert Consensus Panel ${ }^{\mathrm{a}}$
}

\author{
${ }^{1}$ Department of Obstetrics and Gynecology, University of Toronto, Toronto, ON, Canada \\ ${ }^{2}$ EGA Institute for Women's Health, Faculty of Population Health Sciences, University College London, London, UK \\ ${ }^{3}$ Department of Obstetrics and Gynecology, Baylor College of Medicine, Texas Children's Pavilion for Women, Texas Medical Center, Houston, TX, USA \\ ${ }^{*}$ Correspondence \\ Eric Jauniaux, EGA Institute for Women's Health, Faculty of Population Health Sciences, University College London, London, UK. \\ Email: e.jauniaux@ucl.ac.uk \\ "Developed by the FIGO Safe Motherhood and Newborn Health Committee; coordinated by Eric Jauniaux, lead developer and corresponding author. \\ ${ }^{\star}$ The views expressed in this document reflect the opinion of the individuals and not necessarily those of the institutions that they represent. \\ ${ }^{a}$ FIGO Placenta Accreta Diagnosis and Management Expert Consensus Panel members are listed at the end of the paper.
}

\section{1 | INTRODUCTION}

For more than half a century after the first case series of placenta accreta was reported in $1937,,^{1}$ the main and often only approach to management was a cesarean hysterectomy. This approach had the advantage of reducing the immediate risks of major hemorrhage associated with accreta placentation at a time when there was no access to blood transfusion.

Over the last two decades, a variety of conservative options for the management of placenta accreta spectrum (PAS) disorders have evolved, each with varying rates of success, and peripartum and secondary complications. $^{2-4}$ In a recent systematic review and meta-analysis of the outcome of placenta previa accreta diagnosed prenatally, 208 out of 232 (89.7\%) cases had an elective or emergent cesarean hysterectomy. ${ }^{5}$ As a result of a lack of randomized clinical trials, the optimal management of PAS disorders remains undefined and is determined by the capacity to diagnose invasive placentation preoperatively, local expertise, depth of villous invasion, and presenting symptoms. ${ }^{4}$

In cases of high suspicion for PAS disorders during cesarean delivery, the majority of members of the Society for Maternal-Fetal Medicine (SMFM) proceed with hysterectomy and only $15 \%-32 \%$ report conservative management. ${ }^{6,7}$ However, there is considerable practice variation reported on aspects of care around delivery and hysterectomy by both obstetricians and maternal-fetal medicine specialists. ${ }^{6,8}$ There is also wide variation between high-income countries and low- and middle-income countries owing to limited or no access to specialist care and essential additional treatment, such as blood products for transfusion. Hysterectomy remains the definitive surgical treatment for PAS disorders, especially for its invasive forms, and a primary elective cesarean hysterectomy is the safest and most practical option for most low- and middle-income countries where diagnostic, follow-up, and additional treatments are not available. In this chapter, we review the evidence-based data on nonconservative surgery (i.e. cesarean hysterectomy) for the management of PAS disorders.

\section{2 | PREPARATION FOR THE OPERATIVE MANAGEMENT OF INVASIVE PLACENTATION}

Cesarean hysterectomy in the setting of PAS disorders can be challenging because multiple cesarean deliveries often present with pelvic adherences, a thin and hypervascular lower uterine segment, a bulky in-situ placenta, and deep pelvis neovascularization, as well as possible invasion to bladder, bowel, cervix, and parametrium in cases of placenta percreta.

The main risk associated with any form of PAS disorder is massive obstetric hemorrhage, which leads to secondary complications including coagulopathy, multisystem organ failure, and death ${ }^{9-20}$ (Table 1). Surgical risks increase with the depth of placental invasion, with women presenting with placenta percreta more likely to require additional 
TABLE 1 Complications associated with surgery for placenta accreta spectrum (PAS) disorders.

\begin{tabular}{|ll|}
\hline Complications & \\
\hline Median estimation of blood loss & $2-3 \mathrm{~L}$ \\
\hline Median units of packed red blood cells transfused & $3.5-5.4 \mathrm{~L}$ \\
\hline Large-volume blood transfusions (>10 L) & $5 \%-40 \%$ \\
\hline Injury to bladder & $7 \%-48 \%$ \\
\hline Injury to ureter & $0-18 \%$ \\
\hline Admission to intensive care unit & $15 \%-66 \%$ \\
\hline Bowel injury/obstruction & $2 \%-4 \%$ \\
\hline Venous thromboembolism & $4 \%$ \\
\hline Surgical site infection & $18 \%-32 \%$ \\
\hline Reoperation & $4 \%-18 \%$ \\
\hline Maternal mortality & $1 \%-7 \%$ \\
\hline
\end{tabular}

blood products, have urologic injury, and require intensive care unit admission than women with placenta creta (vera or adherenta). ${ }^{10,21,22}$

Accurate prenatal diagnosis, careful planning, and close communication are essential, including the creation of specialized surgical teams to execute a safe care plan for patients with PAS disorders.

\section{1 | Multidisciplinary team care}

Multiple retrospective cohort studies of PAS disorders have documented reduced maternal morbidity when care is provided in centers of excellence (CoE). ${ }^{11,15,17,23}$ The hallmark features of a CoE are listed in Table $2 .{ }^{24}$ While the exact components of care plans may vary from center to center, the common aspects remain a dedicated care plan and a multidisciplinary team (MDT) with surgical expertise capable of managing the full spectrum of accreta complexity.
Recent cohort studies have shown that women managed by MDT care were less likely to require large-volume blood transfusion, intensive care unit admission, and reoperation within 7 days of delivery compared with management by standard obstetric care without a specific protocol $^{11,15,17,23}$ (Table 3). Each component within the care plan is important. In a Canadian prospective chart review of 33 patients within a CoE, stepwise increasing use of MDT components was significantly associated with a reduction in composite morbidity, ${ }^{9}$ which demonstrates the additive value of each component of care. A sufficient volume of cases per year to maintain the experience of the MDT is crucial.

Surgical expertise in complex pelvic surgery is a core principle for management of PAS disorder cases. A single-center retrospective cohort of 98 cases of histologically confirmed PAS disorders showed that the cases where a gynecologic oncologist was on standby but not in the operating room had both higher blood loss and transfusion rates than when oncology was present from the onset. ${ }^{25}$ This supports the early presence of an expert with specific experience in cesarean hysterectomy for PAS disorders and in particular in cases of placenta percreta. This is usually, but not always, a gynecological surgeon and is dependent on the MDT make-up of the team. Within this context, if a "call if needed" approach is not acceptable then the availability of expert MDT care at all times must be ensured. This approach is pivotal in cases of placenta percreta with invasion of the surrounding pelvic organs such as the bladder. Using data from the UK Obstetric Surveillance System registry, a population-based cross-sectional study found that nearly half (49\%) of the women requiring a massive transfusion present with a PAS disorder and $34 \%$ of those present outside working hours. ${ }^{26}$

Overall, MDTs demonstrate ongoing improvements in patient safety with increasing experience and reflective changes in care plans. One study including a total 118 PAS disorder cases that compared two sequential time periods reported reductions in estimated blood

TAB LE 2 Components of multidisciplinary team care within Centers of Excellence for placenta accreta spectrum (PAS) disorders.

\section{Component}

Universal access to multidisciplinary team care

Standard care plan

Radiologic expertise for diagnosis

Experienced obstetrician/maternal-fetal medicine specialist

Surgical Eexpertise for complex surgery (Ggynecologic oncology, pelvic surgeon, urogynecologist)

Anesthetist (obstetrical or trauma)

Neonatal intensive care unit and neonatalogists

Adult intensive care unit and intensivists

Massive transfusion capacity

Additional surgical expertise when required: urology, vascular surgery, general surgeon, trauma surgeon Interventional radiology

Cell saver and perfusionists
24/7 access to the care team to enact care plan in urgent/emergent situations

Consistent and standardized care plan should be established, this can be aided by use of checklists to guideprenatal, intrapartum and postpartum care

Ultrasound and/or MRI

For prenatal diagnosis, prepartum, intrapartum, and postpartum management

Skills for retroperitoneal dissection, ureterolysis, internal iliac artery ligation, ureteral stent placement

Experienced in management of massive hemorrhage as well as perioperative management of pregnant women

To manage both planned late preterm delivery and unplanned preterm delivery Surgical and medical intensive care unit for postoperative care as required

Access to blood products/bank, massive transfusion protocol, transfusion medicine specialists/blood bank pathologists

Management of complications: ureteral reimplantation, bowel resection, vascular injury

For possible placement of intravascular balloons or postoperative selective arterial embolization

If available, may be cost-effective depending on frequency of transfusion of allogenic blood 
TAB LE 3 The impact of multidisciplinary team (MDT) care on the management of placenta accreta spectrum (PAS) disorders.

\begin{tabular}{|c|c|c|c|c|}
\hline Author & $\begin{array}{l}\text { Cohort } \\
\text { size }(n)\end{array}$ & Study design & Comparator & Improvements with MDT care vs control \\
\hline $\begin{array}{l}\text { Eller et al. }{ }^{17} \\
\text { USA }\end{array}$ & 141 & $\begin{array}{r}\text { Retrospective } \\
\text { cohort study }\end{array}$ & $\begin{array}{l}79 \text { MDT centers ( } 2 \text { hospitals) } \\
62 \text { standard obstetric (hospitals) } \\
\text { Centers ( } 26 \text { hospitals) }\end{array}$ & $\begin{array}{l}\text { Large-volume transfusions (4 or more units) } 43 \% \text { vs } 61 \%(P=0.031) \\
\text { Reoperation within } 7 \text { d } 3 \% \text { vs } 36 \%(P<0001) \\
\text { Composite early morbidity } 47 \% \text { vs } 74 \%(P=0.026) \\
\text { Odds ratio of composite early morbidity } 0.22(0.07-0.70)\end{array}$ \\
\hline $\begin{array}{l}\text { Al-Khan et al., }{ }^{15} \\
\text { USA }\end{array}$ & 67 & $\begin{array}{r}\text { Retrospective } \\
\text { cohort study }\end{array}$ & $\begin{array}{l}\text { Before and after institution of a } \\
\text { management protocol in single } \\
\text { institution, early cohort } 25 \text {, late } \\
\text { cohort } 42\end{array}$ & $\begin{array}{l}\text { Estimated blood lossreduced by } 48 \%(P<0.001) \\
\text { Intraoperative packed red blood cell transfusion reduced } \\
\text { by } 40 \%(P<0.01) \\
\text { Total transfused packed red blood cells reduced by } 50 \%(P<0.01) \\
\text { Intensive care unit admissions reduced by }>50 \%(P<0.01)\end{array}$ \\
\hline $\begin{array}{l}\text { Shamshirsaz } \\
\text { et al.., }{ }^{11} \text { USA }\end{array}$ & 90 & $\begin{array}{l}\text { Retrospective } \\
\text { cohort study }\end{array}$ & $\begin{array}{l}\text { Before and after formal program } \\
\text { of standardized MDT in } 3 \\
\text { tertiary hospitals } \\
57 \text { MDT, } 33 \text { non-MDT }\end{array}$ & $\begin{array}{l}\text { Less urgent delivery with MDT } 23 \% \text { vs } 64 \%(P=0.001) \\
\text { Less estimated blood loss with MDT } 2.1 \mathrm{~L}(0.5-18 \mathrm{~L}) \text { vs } 3 \mathrm{~L} \\
(0.8-14)(P=0.008)\end{array}$ \\
\hline $\begin{array}{l}\text { Smulian et al., } \\
\text { USA }\end{array}$ & 47 & $\begin{array}{r}\text { Retrospective } \\
\text { cohort study }\end{array}$ & $\begin{array}{l}\text { Before and after MDT implemented, } \\
\text { single institution } \\
19 \text { MDT, } 28 \text { non-MDT }\end{array}$ & $\begin{array}{l}\text { Less blood loss with MDT } 1.2 \mathrm{~L} \text { vs } 2.5 \mathrm{~L}(P=0.009) \\
\text { Less administration of blood products } 47.4 \% \text { vs } 85.7 \%(P=0.005) \\
\text { Higher intraoperative lowest mean arterial pressures } 57 \mathrm{~mm} \mathrm{Hg} \\
\text { vs } 48 \mathrm{~mm} \mathrm{Hg}(P=0.002)\end{array}$ \\
\hline
\end{tabular}

loss, proportion of women receiving blood transfusions, proportions of large-volume blood transfusions, and use of massive blood transfusion protocols over time within a well-established MDT. ${ }^{27}$ However, the improvements in maternal morbidity were only demonstrated for increta and percreta cases, highlighting the importance of MDT experience with the complex and more invasive forms of PAS disorders.

Despite the clear benefits of decreased maternal morbidity, no benefit or adverse effect on neonatal outcomes has been demonstrated with MDT care for PAS disorders in CoE. ${ }^{11,15}$ Operative times with MDTs may be significantly longer. Surgeries in a single center were $260 \pm 68$ minutes with the team and $181 \pm 57$ minutes in the absence of the MDT, likely as a result of introducing more aspects of care. ${ }^{23}$ It is also possible that the MDT becomes involved with the more complex cases that simply require more time to set up and perform. These longer operating times may affect resource utilization and are not available in low-income and most middle-income countries.

\subsection{Timing of delivery}

Studies reporting actual timing of delivery are conflicting and the optimal timing of delivery for women with suspected PAS disorders remains uncertain. At present, there remains insufficient evidence to determine the exact optimal age for planned delivery. Different centers have published varying protocols with recommendations ranging from 34 to 36 weeks to 36-38 weeks of gestational age for planned

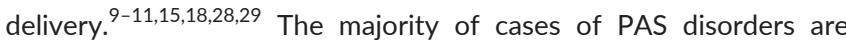
now associated with placenta previa, ${ }^{13,14}$ and thus as gestational age increases the likelihood of major prepartum hemorrhage increases.

Scheduled nonemergent deliveries result in a significant reduction in maternal morbidity due to PAS disorders. Complications related to blood loss are lower in nonemergent compared with emergent deliveries. ${ }^{12,13,16}$ This knowledge has led to the scheduling of surgical interventions with planned late preterm (35-36 weeks) or early term ( 37 weeks) delivery as a mechanism to avoid the need for emergency surgery. An MDT care plan that included planned delivery at 34-35 weeks demonstrated a reduction in emergency deliveries from $23 \%$ to $64 \%$ with no adverse effects on neonatal outcomes. ${ }^{11}$

A decision tree analysis comparing strategies for delivery of women with placenta previa accreta from 34 to 39 weeks demonstrated that under a variety of circumstances, delivery at 34 weeks after administration of corticosteroid for lung maturity may be the preferred timing as reflected in quality-adjusted life years. ${ }^{30}$ There is no role for assessing fetal lung maturity with amniocentesis and little benefit is gained from expectant management beyond 37 weeks. Modelling did indicate that when the risk of prepartum hemorrhage is low, delivery at 37 weeks may be optimal.

A retrospective cohort study of 77 women with suspected PAS disorders found that women who delivered prior to a planned delivery date were significantly more likely to have had prior prepartum hemorrhage and uterine activity compared with women who had a scheduled delivery. Each episode of prepartum hemorrhage is associated with an increased risk of unscheduled delivery ( $\mathrm{OOR} 3.8,95 \% \mathrm{Cl} 1.8-7.8$ ). The interval to delivery further decreases when bleeding is associated with preterm premature rupture of membranes (PPROM). Thus the women who may benefit the most from a strategy of planned late preterm delivery are those with a history of episodes of prepartum hemorrhage, PPROM, or uterine contractions. ${ }^{28,29}$ The corollary remains that women who are stable with no prepartum hemorrhage, PPROM, or uterine contractions may be considered for planned delivery at 36-37 weeks.

Overall, in women with episodes of prepartum hemorrhage, especially recurrent, PPROM, and contractions, planned preterm delivery may be warranted. Risks of urgent delivery to maternal health must be balanced with the neonatal complications associated with late preterm delivery.

\section{3 | Maximizing hemoglobin preoperatively}

Owing to the anticipated risk of hemorrhage at delivery, preoperative optimization of hemoglobin is essential. The prevalence of anemia in 
pregnancy may be as high as $38 \%$, with the majority caused by iron deficiency. Women in low-income countries are at even higher risk due to malnutrition and/or pre-existing diseases such as malaria or sickle cell anemia. Prenatal correction of iron deficiency anemia is an important consideration in management of PAS disorders. Oral or intravenous iron therapy if available should be administered if iron deficiency anemia is confirmed. Intravenous iron therapy is safe in pregnancy and has been demonstrated to correct anemia in more women than oral iron. ${ }^{31}$ In addition, efficacy with a single dose intravenous therapy is possible. ${ }^{32}$ There are some centers where, resources permitting, erythropoietin therapy is combined with concomitant intravenous iron treatment.

\section{4 | Minimizing unintended urologic injury}

In a systematic review of surgical techniques used for PAS disorders, the overall rate of unintentional urinary tract injury at peripartum hysterectomy was $29 \%$ (83/285)-higher than rates for hysterectomies for other gynecologic indications. ${ }^{33}$ Seventy-eight percent of injuries involve the bladder, whereas $17 \%$ involve the ureter. ${ }^{33}$ Modification of surgical technique has the ability to reduce urinary tract injury compared with standard hysterectomy. ${ }^{33}$ In particular, placement of ureteric stents preoperatively can reduce the risk of urinary tract injury from $33 \%$ to $6 \% .{ }^{33}$ At ureteric stent placement, cystoscopic assessment can also evaluate for evidence of bladder invasion by the placenta. Inconsistent use of stents across studies is ascribed to surgeon preference. ${ }^{19,33}$ Ureteral stents or catheters are more commonly used in the USA where $26.2 \%-35 \%$ of maternal fetal medicine specialists and $26.3 \%$ of ACOG fellows use them in the management of PAS disorders. $^{6-8}$ Opening the retroperitoneal space and visualizing the ureters can be helpful and may prevent inadvertent damage to the ureter. ${ }^{16}$

Clinical symptoms of bladder invasion are rare. In a review of the published literature including 20 cases of bladder invasion, only a quarter presented with gross hematuria. ${ }^{34}$ Hence, most commonly, preoperative cystoscopy and the placement of ureteral stents are recommended when urinary bladder invasion is suspected on prenatal imaging. ${ }^{11,15,19}$ Greater depth of placental invasion is associated with urologic injury. ${ }^{22}$ For placenta percreta with bladder involvement, some authors recommend deliberate cystotomy, identification of the percreta villous tissue, and excision of the involved bladder rather than difficult dissection. ${ }^{11,35}$

The other major factor to avoid urinary tract injury is to avoid major intraoperative bleeding, which will both limit visibility and create urgency for bladder dissection. Urologic injuries have been shown to increase when intraoperative blood loss is greater. ${ }^{22}$ Dissection of the bladder first, prior to delivery, has been shown to allow sufficient time to identify and create the vesicouterine plane before an intraoperative bleed, which will make the identification of the different tissues difficult. $^{33}$ In particular, in some cases of placenta percreta the abundance of the newly formed vessels might complicate the dissection of the bladder and cause profuse bleeding.

In those cases where there is extensive anterior and lateral invasion or bulging of the thinned-out uterus into the lateral pelvic sidewalls, adopting a posterior approach may allow stepwise devascularization of the uterus and may aid in the hysterectomy. ${ }^{36}$
Putting patients in the lithotomy position in stirrups improves evaluation of the amount of intraoperative bleeding. Filling the bladder before the surgical procedure helps in the dissection of the lower segment and allows for an easier cystotomy, when needed, and better detection of the cervix during total hysterectomy. ${ }^{16}$

\section{3 | INTRAOPERATIVE CONSIDERATIONS}

\section{1 | Anesthesia}

The choice of anesthesia technique for cesarean delivery where there is a suspected PAS disorder with high risk of significant hemorrhage must be made by the attending anesthesia team. This decision between general and neuraxial/regional anesthesia can be aided through active consultation with the wider MDT.

There are several factors to consider that can influence this decision (Box 1). Historically, most patients with PAS disorders were managed conservatively with general anesthesia, as described in a retrospective study of 26 maternity hospitals in Israel. ${ }^{37}$ Recently, greater experience has permitted more frequent use of epidural with or without spinal. When managed appropriately and in an elective situation, most patients can tolerate both prolonged and extensive surgery with significant associated blood loss using these techniques. ${ }^{38-40}$

The international literature reports an $8 \%-45 \%$ risk of the need to convert from regional to general anesthesia for cases of PAS disorders. ${ }^{40-43}$ Most of these occur when there is no prior suspicion of PAS disorders and the diagnosis is made intraoperatively. The highest rates of conversion appear to occur in low-income countries, which also have higher rates of reported blood loss; therefore, general anesthesia may be the initial method of choice in this context. ${ }^{41}$

Several studies have reported decreased hemorrhage-related morbidity and blood transfusion requirements at cesarean delivery

\section{Box 1 Factors to consider in selection of anesthesia for placenta accreta spectrum (PAS) disorders.}

\section{Criteria for consideration}

Patient preference

Body habitus (body mass index, potentially difficult patient airway)

American Society of Anesthesiologists Score

Available resources

Anesthetist experience

Regional anesthesia effectiveness

State of emergency

Hemodynamic stability

Ability to manage patient in hypovolemic shock

Ability to perform a rapid emergent tracheal intubation

Patient co-morbidities

Potential complication

Secondary benefits, i.e. patient-controlled epidural anesthesia for postoperative pain management with midline laparotomy 
with regional compared with general anesthesia. ${ }^{44,45}$ Of these, one randomized clinical trial was specifically designed to study women with placenta previa including accreta, and while it demonstrated that blood transfusion requirements were greater in the general anesthesia group, there was no significant difference in reported blood loss overall. ${ }^{44}$ No significant difference in blood loss or volume of blood transfused between regional and general anesthesia was found in a recent retrospective cohort of 50 cases of placenta accreta managed by a single Canadian $\mathrm{CoE}{ }^{43}$

Neonatal outcomes, in particular neonatal respiratory complications, appear to be improved with the use of regional compared with general anesthesia, primarily through the avoidance of volatile agents crossing the placenta. ${ }^{43}$

\section{2 | Type of incisions for access}

Avoiding the placenta at planned cesarean hysterectomy reduces blood loss; therefore, the abdominal incision must allow sufficient access to the uterus to choose a location for hysterotomy above the upper placental margin. Preoperative or intraoperative ultrasound can allow the team to visualize the upper placental margin, which facilitates planning both the abdominal and uterine incision. ${ }^{15,46}$

A low transverse skin incision that allows access to the lower half of the uterus may be adequate if the upper margin of the placenta does not rise into the upper segment of the uterus and no hysterectomy is planned. However, it may not provide sufficient exposure in cases of placenta percreta. If the placenta is anterior and extending toward the level of the umbilicus, and/or a hysterectomy is planned, a midline skin incision allows for a high upper-segment transverse uterine incision above the upper margin of the placenta or more commonly a fundal transverse hysterotomy for delivery of the infant. Thus, a midline incision is recommended by most authors for PAS disorders diagnosed prenatally or at the time of cesarean delivery. ${ }^{11,15,18,35,46}$ The Joel-Cohen incision ( $4-5 \mathrm{~cm}$ widths above the pubic symphysis) or a Cherney extended transverse incision (transection of the rectus muscles at their insertion on the pubic symphysis or a vertical incision of the fascia abdominalis) could be used to avoid a vertical incision or allow increased visibility, but there are no available data on the use of these types of incisions in the management of PAS disorders. Utilizing a fetal surgery approach to hysterotomy, with either a uterine stapler or Smith-Opitz clamps, can reduce blood loss dramatically but this is only available in a few CoE in high-income countries.

\section{3 | Blood conservation techniques}

\subsection{1 | Tranexemic acid}

Tranexamic acid is a widely available hemostatic antifibrinolytic agent that inhibits the enzymatic breakdown of fibrinogen and fibrin by plas$\mathrm{min}$. It is relatively inexpensive and available in oral tablet and injectable solution forms that have a long shelf life at less than $30^{\circ} \mathrm{C}$. Significant international efforts have culminated in several studies investigating tranexamic acid in obstetric trauma and postpartum hemorrhage.
Most recently, a large double-blind placebo-controlled trial recruited over 20000 patients with postpartum hemorrhage to the WOMAN trial. ${ }^{47}$ The study demonstrated that, compared with placebo, tranexamic administration significantly reduced death due to massive obstetric hemorrhage without increasing rates of adverse events, including thromboembolism.

A recent meta-analysis of nine trials involving 2365 patients confirmed these findings, demonstrating that the administration of tranexamic acid before cesarean delivery significantly reduces intraand postoperative blood loss and blood transfusion with no increase in thromboembolic events. ${ }^{48}$ After this analysis, three more placebocontrolled trials have shown that tranexamic acid administration immediately before cesarean delivery significantly reduces reported intraoperative blood loss and postoperative declines in hemoglobin without any increase in adverse maternal or neonatal effects. ${ }^{49-51}$

No trials have specifically examined the role of tranexamic acid in the surgical management of PAS disorders. However, the quality of the evidence on postpartum hemorrhage justifies its use in the management of women diagnosed prenatally or presenting with PAS disorders at the time of delivery.

\subsection{2 | Balloon occlusion catheters}

A large number of studies, mostly retrospective, have evaluated the role of prophylactic placement of balloon occlusion catheters to mitigate bleeding at the time of cesarean hysterectomy for PAS disorders, with varied results. ${ }^{52-73}$ These devices are usually inserted by specialist interventional radiologists into the aorta, common iliac, internal iliac, or uterine arteries under fluoroscopic guidance and are inflated when hemorrhage is encountered. Many authors have advocated their use, claiming a decrease in blood loss and transfusion requirements, and improved visualization on the surgical field. ${ }^{52-68}$ However, other studies fail to demonstrate any benefit and criticize their use. ${ }^{69-73}$ These authors claim that occlusive balloons cannot prevent catastrophic bleeding since the blood supply to the pelvis is maintained by the development of rich collaterals during pregnancy. ${ }^{73,74}$ In fact, they postulate that the empiric inflation of these balloons in a relatively dry setting may actually exacerbate bleeding from such collaterals. ${ }^{71-74}$ Finally, reports of vessel rupture and thromboembolic catheter-related complications have called into question these balloons' risk-benefit ratio. ${ }^{75-81}$

Well-designed randomized controlled trials are needed to truly demonstrate the safety and efficacy of these devices and to establish whether certain subgroups of patients with PAS disorders would derive more benefit (i.e. more invasive placentation). ${ }^{82}$ Currently, the evidence available is insufficient to make firm recommendations on their use.

\subsection{3 | Internal Iliac artery ligation}

Advantages to surgically ligating the internal iliac arteries are similar to those for balloon occlusion devices. However, with the proper skillset, surgical internal iliac artery ligation has the added benefit of being available in low- and middle-income countries, where access to interventional radiology may be limited. 
Studies evaluating the safety and effectiveness of internal iliac artery ligation in the context of PAS disorders specifically are few. In a study by Grace Tan et al., ${ }^{10} 44 \%$ of patients underwent bilateral internal iliac artery ligation prior to hysterectomy for placenta accreta; however, transfusion requirements were the same as for those who did not under ligation. ${ }^{10}$ In a smaller study of 23 cases, 15 of whom underwent internal iliac artery ligation, no differences in mean blood loss or blood loss greater than $5 \mathrm{~L}$ was demonstrated with and without ligation. ${ }^{38}$

\subsection{4 | Cell salvage}

Autologous cell salvage offers a way to minimize allogenic red blood cell transfusion in select patients, such as those with high risk of massive obstetric hemorrhage, low preoperative hemoglobin concentrations, rare blood types (e.g. Bombay), and/or those who refuse such products including Jehovah's witnesses. ${ }^{83,84}$ Whilst cell salvage and retransfusion are viewed as relatively expensive and labor intensive, autologous cell salvage is now being adopted in many obstetric centers managing PAS disorders, with observational studies showing improved outcomes and reduced need for allogenic blood transfusion, without an increase in adverse outcomes. ${ }^{84-86}$ Regarding cost analysis, a recent study demonstrated that intraoperative cell salvage during cesarean delivery for invasive placentation justified its use where the probability of requiring packed red cell transfusion of two units was $75 \%{ }^{87}$
It is important that suctioned contaminants are kept to an absolute minimum, including amniotic fluid, vernix, microorganisms, fetal blood, and exogenous surgical solutions such as contemporary hemostatics. ${ }^{88}$ These may not be filtered adequately by cell salvage equipment and may be reinfused directly into the maternal circulation with theoretical complications including embolism, isoimmunization and thrombosis.

\subsection{5 | Placental removal}

Attempt to remove an undiagnosed PAS disorder at cesarean delivery is known to lead to uncontrolled hemorrhage. These risks are of particular concern when the delivery takes place in an environment with no emergency access to blood bank products and expertise in managing PAS disorders. A retrospective study of 57 cases of suspected PAS disorders demonstrated significantly reduced short-term morbidity if the placenta is left in place and hysterectomy performed electively compared with attempting to remove the placenta first. ${ }^{12}$ In two additional retrospective cohorts, MDT care was associated with statistically lower rates of attempted placental removal and a reduction in blood transfusion rates, large-volume blood transfusion, and estimated blood loss for PAS disorders. ${ }^{17,23}$ However, in select patients, intraoperative inspection of the uterus at cesarean delivery may allow a trial of placental separation in suspected cases of PAS disorders without increasing morbidity. ${ }^{89}$ This study had a high rate of

TAB LE 4 Novel techniques for cesarean hysterectomy in patients with placenta accreta spectrum (PAS) disorders.

\begin{tabular}{|c|c|c|}
\hline Author (n) & Technique & Description of Modification \\
\hline Selman ${ }^{97}$; Chile $(n=11)$ & $\begin{array}{l}\text { Posterior retrograde } \\
\text { hysterectomy via } \\
\text { pouch of Douglas }\end{array}$ & $\begin{array}{l}\text { After closure of hysterotomy, uterus is exteriorized, round ligaments are divided, retroperitoneal } \\
\text { space dissected parallel to ureters and pelvic side wall vessels, utero-ovarian ligaments are } \\
\text { divided bilaterally: } \\
\text { 1. Posterior vaginal fornix exposed with sponge stick into vagina and opened transversely below } \\
\text { cervicovaginal junction } \\
\text { 2. Vagina circumscribed with clamps, divided and ligated } \\
\text { 3. Ureters identified, dissected, and preserved though anterior bladder pillar } \\
\text { 4. Cervix grasped, pulled up behind uterus } \\
\text { 5. Cardinal ligaments, uterosacrals, and bladder pillars are sequentially divided } \\
\text { 6. Vesicouterine space is developed until bladder detached from anterior aspect of uterus or } \\
\text { cystotomy and resection of posterior bladder wall if placental invasion }\end{array}$ \\
\hline
\end{tabular}

\begin{tabular}{ll}
$\begin{array}{l}\text { Shamshirsaz et al. }{ }^{11 ;} ; \\
\text { USA ( } n=57)\end{array}$ & $\begin{array}{l}\text { Modified radical } \\
\text { hysterectomy } \\
\text { technique and use of } \\
\text { bipolar cautery devi }\end{array}$ \\
\hline $\begin{array}{l}\text { Belfort et al. }{ }^{90} ; \\
\text { USA ( } n=3)\end{array}$ & $\begin{array}{l}\text { Linear cutting } \\
\text { staple device for } \\
\text { hysterotomy }\end{array}$
\end{tabular}

Shamshirsaz et al. ${ }^{11}$

Wide margins to avoid clamping fragile/unsupported vessels and or/thinned myometrium

1. Retroperitoneum accessed lateral to round ligaments, ureters, internal iliac vessels identified. Ureterolysis performed if required.

2. Uterus separated from support structures with wide margin on broad ligament

3. Stepwise devascularization of lower uterine segment

4. If required identification and ligation of superior vesical arteries

5. Intentional cystotomy and excision of bladder if invasion

Midline abdominal incision, uterus exteriorized, and site of hysterotomy identified high on upper uterine segment of fundus

1. Uterine wall grasped to create fold of uterus

2. Placement of 4 full-thickness sutures in box patter to create unperfused area of upper uterine segment

3. Create initial entry in "box" with diathermy

4. Membranes dissected away from uterine wall digitally to create space for stapler

5. Linear cutting staple device inserted and deployed 1 to 3 times as required to create hysterotomy

Rossetti et al. ${ }^{91}$; Italy ( $n=49,20$ accreta)
Use of vessel-sealing devices for Peripartum Hysterectomy
Vessel sealing device used to facilitate surgery 
non-confirmation of PAS disorders (45/99) and the authors provided no details of the depth of placental invasion.

Response to a survey of SMFM providers in the USA indicated that $60 \%$ attempt placental removal with PAS disorders. However, providers with more experience in PAS disorder management (as assessed by the number of cases per year) were less likely to attempt placental removal. ${ }^{6}$ This is consistent with evidence from retrospective cohort studies, demonstrating fewer attempts at placental removal by MDTs in CoE.

Overall, in the setting of planned immediate hysterectomy for PAS disorders, no attempt at manual separation should be undertaken because leaving the placenta in situ is associated with lower blood loss. If spontaneous partial separation occurs, management as per conservative therapy strategies could be employed if the accreta portion of the placenta is limited in depth and laterally. Therefore, uterotonic agents are not administered at cesarean hysterectomy for PAS disorders, unless placental removal is imminent ${ }^{35}$ or complete placental separation occurs thus ruling out PAS disorders.

\section{4 | TECHNIQUES FOR HYSTERECTOMY}

\subsection{Total versus subtotal hysterectomy}

Total hysterectomy is the recommended surgical method for emergent peripartum hysterectomy owing to the potential risk of malignancy developing in the cervical stump, the need for regular cervical cytology, and other associated problems such as bleeding or discharge. Proponents of subtotal hysterectomy report decreased blood loss, blood transfusions, perioperative complications, and shorter operating time. However, subtotal hysterectomy may not be effective in the management of placenta increta or percreta if cervical involvement is present and a total hysterectomy should be the preferred option in these cases. In addition, subtotal hysterectomy has not been shown to provide protection against urinary tract injury compared with total hysterectomy in surgeries for PAS disorders. ${ }^{33}$

The survey of SMFM specialists regarding their management of PAS disorders was split with regard to the use of total versus subtotal hysterectomy. Just over half $(55 \%)$ of all providers performed total procedures, with $45 \%$ reporting use of supracervical hysterectomy. ${ }^{6}$

\subsection{Other novel surgical techniques}

Numerous centers have modified their surgical techniques in an attempt to minimize hemorrhage and/or to reduce unintentional injury to the urinary tract. ${ }^{11,36,90,91}$ These techniques involve early devascularization and use of disposable devices such as stapling or vessel sealing devices (Table 4).

\section{3 | Planned delayed hysterectomy}

Planned delayed or secondary hysterectomy is an alternative "definitive" surgical management strategy for PAS disorders. Delayed hysterectomy may be undertaken where extensive invasion (percreta) of surrounding structures would render immediate cesarean hysterectomy extremely difficult. Allowing some resorption of the placenta, decrease in vascularity and involution of the uterus is postulated to facilitate later surgery. However, there is an associated risk of coagulopathy, hemorrhage, and sepsis during the interim period. Patients must be compliant with follow-up and resources to manage patients urgently if complications arise should be available 24 hours a day.

Delayed hysterectomies are performed between 3 and 12 weeks postpartum ${ }^{15,92,93}$ and many cases involve postdelivery uterine artery embolization or internal iliac artery ligation and thus possible adverse effects and secondary complications. ${ }^{15,92-94}$ The estimated blood loss in this staged surgical approach, including both initial delivery and subsequent hysterectomy, has been reported to be less or similar to immediate surgery. ${ }^{15,92,94}$ Delaying hysterectomy in complex cases may reduce other surgical morbidity. In the systematic review of urinary tract injury rates with PAS disorders, there were no reported unintentional urologic complications in nine cases of delayed hysterectomy; however, this was not statistically significant when compared with immediate management. Intentional cystotomy and partial cystectomy were still required in three of the second surgeries (33\% of the cases). ${ }^{33}$

While traditionally these second surgeries involve a laparotomy, minimally invasive surgical approaches including robotics have been reported. ${ }^{92,94-96}$ This approach requires advanced skills but may have enhanced visualization compared with laparotomy, along with shorter recovery, although surgical times are quite prolonged (up to 286330 minutes). ${ }^{92-96}$ These techniques require care in CoE with both advanced surgical programs and the capacity to manage emergent massive obstetric hemorrhage.

\section{5 | RECOMMENDATIONS}

Recommendations for the surgical nonconservative management of PAS disorders are given in Table 5.

\section{CONSENSUS PANEL}

Greg Duncombe (Australia and New Zealand), Philipp Klaritsch (Germany), Frédéric Chantraine (Belgium), John Kingdom (Canada), Lene Grønbeck (Denmark), Kristiina Rull (Estonia), Balkachew Nigatu (Ethiopia), Minna Tikkanen (Finland), Loïc Sentilhes (France), Tengiz Asatiani (Georgia), Wing-Cheong Leung (Hong Kong), Taghreed Alhaidari (Iraq), Donal Brennan (Ireland), Eiji Kondoh (Japan), Jeong-In Yang (South Korea), Muhieddine Seoud (Lebanon), Ravindran Jegasothy (Malaysia), Salvador Espino y Sosa (Mexico), Benoit Jacod (Netherlands), Francesco D'Antonio (Norway), Nusrat Shah (Pakistan), Dorota Bomba-Opon (Poland), Diogo Ayresde-Campos (Portugal), Katarina Jeremic (Serbia), Tan Lay Kok (Singapore), Priya Soma-Pillay (South Africa), Nataša Tul Mandić (Slovenia), Pelle Lindqvist (Sweden), Thora Berglind Arnadottir (Sweden), Irene Hoesli (Switzerland), Unnop Jaisamrarn (Thailand), Amal AI Mulla (United Arab Emirates), Stephen Robson (UK), Rafael Cortez (Venezuela). 
TAB LE 5 Recommendations for the surgical nonconservative management of placenta accreta spectrum (PAS) disorders.

\begin{tabular}{|c|c|c|}
\hline Recommendations & $\begin{array}{l}\text { Resource } \\
\text { settings }\end{array}$ & $\begin{array}{l}\text { Quality of evidence and } \\
\text { strength of recommendation }\end{array}$ \\
\hline $\begin{array}{l}\text { Women presenting with PAS disorders with or without placenta previa should have their delivery } \\
\text { scheduled in a Center of Excellence with a dedicated multidisciplinary team and care plan }\end{array}$ & High & Moderate and Strong \\
\hline $\begin{array}{l}\text { The care plan for women with PAS disorders should include logistic support for access to blood } \\
\text { products, capacity to perform complex pelvic surgery, intensive care facilities (adult and neonatal), } \\
\text { and obstetric anesthetists }\end{array}$ & High & Moderate and Strong \\
\hline Surgical expertise in complex pelvic surgery should be available throughout the surgical procedure & All & Moderate and Strong \\
\hline $\begin{array}{l}\text { Scheduled nonemergent delivery is advisable for women with PAS disorders as it is associated with a } \\
\text { reduction in complications related to blood loss }\end{array}$ & All & Low and Strong \\
\hline $\begin{array}{l}\text { Deliberate cystotomy and excision of involved bladder may be considered in cases of percreta villous } \\
\text { tissue involving the bladder }\end{array}$ & All & Low and Strong \\
\hline $\begin{array}{l}\text { A midline skin incision should be considered for invasive PAS disorders and anterior low-lying placenta } \\
\text { or previa accreta when the superior margin is outside the lower uterine segment }\end{array}$ & All & Low and Weak \\
\hline $\begin{array}{l}\text { Where available, tranexamic acid should be administered ( } 1 \text { g slow IV or 1000-1300 mg orally) } \\
\text { immediately prior to or during cesarean delivery for PAS disorders }\end{array}$ & All & High and Strong \\
\hline $\begin{array}{l}\text { The role of bilateral internal iliac artery ligation at the time of cesarean hysterectomy for PAS } \\
\text { disorders is currently unclear }\end{array}$ & All & Low and Weak \\
\hline $\begin{array}{l}\text { When available, cell salvage may be utilized or be on "stand-by" during cases of cesarean delivery } \\
\text { for PAS disorders }\end{array}$ & High & Low and Strong \\
\hline $\begin{array}{l}\text { In the absence of spontaneous placental separation, the placenta should be left in situ to minimize } \\
\text { blood loss during planned immediate cesarean hysterectomy and uterotonics should not be used }\end{array}$ & All & Moderate and Strong \\
\hline $\begin{array}{l}\text { Total hysterectomy with placenta in situ is preferred over subtotal hysterectomy in cases of } \\
\text { placenta previa increta or percreta }\end{array}$ & All & Low and Strong \\
\hline $\begin{array}{l}\text { In cases of placenta percreta with extensive pelvic invasion, delayed hysterectomy with placenta } \\
\text { in situ may be considered }\end{array}$ & High & Low and Weak \\
\hline
\end{tabular}

\section{CONFLICTS OF INTEREST}

The authors have no conflicts of interest.

\section{REFERENCES}

1. Irving FC, Hertig AT. A study of placenta accreta. Surg Gynec Obstet. 1937;64:178-200.

2. Clausen C, Lonn L, Langhoff-Roos J. Management of placenta percreta: A review of published cases. Acta Obstet Gynecol Scand. 2014;93:138-143.

3. Amsalem H, Kingdom JC, Farine D, et al. Planned caesarean hysterectomy versus "conserving" caesarean section in patients with placenta accreta. J Obstet Gynaecol Can. 2011;33:1005-1010.

4. Jauniaux E, Collins SL, Jurkovic D, Burton GJ. Accreta placentation: A systematic review of prenatal ultrasound imaging and grading of villous invasiveness. Am J Obstet Gynecol. 2016;215: 712-721.

5. Jauniaux E, Bidhe A. Prenatal ultrasound diagnosis and outcome of placenta previa accreta after caesarean delivery: A systematic review and meta-analysis. Am J Obstet Gynecol. 2017;217:27-36.

6. Esakoff TF, Handler SJ, Granados JM, Caughey AB. PAMUS: Placenta accreta management across the United States. J Matern Fetal Neonatal Med. 2012;25:761-765.

7. Jolley JA, Nageotte MP, Wing DA, Shrivastava V. Management of placenta accreta: A survey of Maternal-Fetal Medicine practitioners. $J$ Matern Fetal Neonatal Med. 2012;25:756-760.

8. Wright JD, Silver RM, Bonanno C, et al. Practice patterns and knowledge of obstetricians and gynecologists regarding placenta accreta. J Matern Fetal Neonatal Med. 2013;26:1602-1609.
9. Walker MG, Allen L, Windrim RC, et al. Multidisciplinary management of invasive placenta previa. J Obstet Gynaecol Can. 2013;35:417-425.

10. Grace Tan SE, Jobling TW, Wallace EM, McNeilage L, Manolitsas T, Hodges RJ. Surgical management of placenta accreta: A 10-year experience. Acta Obstet Gynecol Scand. 2013;92:445-450.

11. Shamshirsaz AA, Fox KA, Salmanian B, et al. Maternal morbidity in patients with morbidly adherent placenta treated with and without a standardized multidisciplinary approach. Am J Obstet Gynecol. 2015;212:218.e1-218.e9.

12. Eller AG, Porter TF, Soisson P, Silve RM. Optimal management strategies for placenta accreta. BJOG. 2009;116:648-654.

13. Warshak CR, Ramos GA, Eskander R, et al. Effect of predelivery diagnosis in 99 consecutive cases of placenta accreta. Obstet Gynecol. 2010;115:65-69.

14. Wright JD, Pri-Paz S, Herzog TJ, et al. Predictors of massive blood loss in women with placenta accreta. Am J Obstet Gynecol. 2011;205:38. e1-38.e6.

15. Al-Khan A, Gupta V, Illsley NP, et al. Maternal and fetal outcomes in placenta accreta after institution of team-managed care. Reprod Sci. 2014; $21: 761$.

16. Seoud MA, Nasr R, Berjawi GA, et al. Placenta accreta: Elective versus emergent delivery as a major predictor of blood loss. J Neonatal Perinatal Med. 2017;10:9-15.

17. Eller AG, Bennett MA, Sharshiner M, et al. Maternal morbidity in cases of placenta accreta managed by a multidisciplinary care team compared with standard obstetric care. Obstet Gynecol. 2011;117:331-337.

18. Camuzcuoglu A, Vural M, Hilali NG, et al. Surgical management of 58 patients with placenta praevia percreta. Wien Klin Wochenschr. 2016;128:360-366.

19. Norris BL, Everaert W, Posma E, et al. The urologist's role in multidisciplinary management of placenta percreta. BJU Int. 2016;117:961-965. 
20. Wright JD, Herzog TJ, Shah M, et al. Regionalization of care for obstetric hemorrhage and its effect on maternal mortality. Obstet Gynecol. 2010;115:194-200.

21. Brookfield KF, Goodnough LT, Lyell DJ, Butwick AJ. Perioperative and transfusion outcomes in women undergoing cesarean hysterectomy for abnormal placentation. Transfusion. 2014;54:1530-1536.

22. Woldu SL, Ordone MA, Devin PC, Wright JD. Urologic considerations of placenta accreta: A contemporary tertiary care institutional experience. Urol Int. 2014;93:74-79.

23. Smulian JC, Pascual AL, Hesham H, et al. Invasive placental disease: The impact of a multi-disciplinary team approach to management. J Matern Fetal Neonatal Med. 2017;30:1423-1427.

24. Silver RM, Fox KA, Barton JR, et al. Center of excellence for placenta accreta. Am J Obstet Gynecol. 2015;212:561-568.

25. Brennan DJ, Schulze B, Chetty N, et al. Surgical management of abnormally invasive placenta: A retrospective cohort study demonstrating the benefits of a standardized operative approach. Acta Obstet Gynecol Scand. 2015;94:1380-1386.

26. Green L, Knigh M, Seeney F, et al. The haematological features and transfusion management of women who required massive transfusion for major obstetric haemorrhage in the UK: A population based study. BrJ Haematol. 2016;172:616-624.

27. Shamshirsaz AA, Fox KA, Erfani $\mathrm{H}$, et al. Multidisciplinary team learning in the management of the morbidly adherent placenta: Outcome improvements over time. Am J Obstet Gynecol. 2017;216: 612.e1-612.e5.

28. Bowman ZS, Manuck TA, Eller AG, Simon M, Silver RM. Risk factors for unscheduled delivery in patients with placenta accreta. Am J Obstet Gynecol. 2014;210:241.e1-241.e6.

29. Rac MW, Wells CE, Twickler DM, Moschos E, McIntire DD, Dashe JS. Placenta accreta and vaginal bleeding according to gestational age at delivery. Obstet Gynecol. 2015;125:808-813.

30. Robinson BK, Grobman WA. Effectiveness of timing strategies for delivery of individuals with placenta previa and accreta. Obstet Gynecol. 2010;116:835-842.

31. Breymann C, Milman N, Mezzacasa A, Bernard R, Dudenhausen J; FER-ASAP Investigators. Ferric carboxymaltose vs. oral iron in the treatment of pregnant women with iron deficiency anemia: An international, open-label, randomized controlled trial (FER-ASAP). J Perinat Med. 2017;45:443-453.

32. Wong L, Smith S, Gilstrop M, et al. Safety and efficacy of rapid (1,000 $\mathrm{mg}$ in $1 \mathrm{hr}$ ) intravenous iron dextran for treatment of maternal iron deficient anemia of pregnancy. Am J Hematol. 2016;91:590-593.

33. Tam Tam KB, Dozier J, Martin JN Jr. Approaches to reduce urinary tract injury during management of placenta accreta, increta, and percreta: A systematic review. J Matern Fetal Neonatal Med. 2012;25: 329-334.

34. Abbas F, Talati J, Wasti S, Akra S, Ghaffar S, Qureshi R. Placenta percreta with bladder invasion as a cause of life threatening hemorrhage. J Urol. 2000;164:1270-1274.

35. Matsubara S, Kuwata T, Usui R, et al. Important surgical measures and techniques at cesarean hysterectomy for placenta previa accreta. Acta Obstet Gynecol Scand. 2013;92:372-377.

36. Belfort MA, Shamshirsaz AA, Fox KA. A technique to positively identify the vaginal fornices during complicated postpartum hysterectomy. Am J Obstet Gynecol. 2017;217:222.e1-222.e3.

37. loscovich A, Shatalin D, Butwick AJ, Ginosar Y, Orbach-Zinger S, Weiniger CF. Israeli survey of anesthesia practice related to placenta previa and accreta. Acta Anaesthesiol Scand. 2016;60:457-464.

38. Iwata A, Murayama Y, Itakura A, Baba K, Seki H, Takeda S. Limitations of internal iliac artery ligation for the reduction of intraoperative hemorrhage during cesarean hysterectomy in cases of placenta previa accreta. J Obstet Gynaecol Res. 2010;36:254-259.

39. Lilker SJ, Meyer RA, Downey KN, Macarthur AJ. Anesthetic considerations for placenta accreta. Int J Obstet Anesth. 2011;20:288-292.
40. Taylor NJ, Russell R. Anaesthesia for abnormally invasive placenta: A single-institution case series. Int J Obstet Anesth. 2017;30:10-15.

41. Munoz LA, Mendoza GJ, Gomez M, Reyes LE, Arevalo JJ. Anesthetic management of placenta accreta in a low-resource setting: A case series. Int J Obstet Anesth. 2015;24:329-334.

42. Kocaoglu N, Gunusen I, Karaman S, Ergenoglu AM, Firat V. Management of anesthesia for cesarean section in parturients with placenta previa with/without placenta accreta: A retrospective study. Ginekol Pol. 2012;83:99-103.

43. Nguyen-Lu N, Carvalho JC, Kingdom J, Windrim R, Allen L, Balki M. Mode of anesthesia and clinical outcomes of patients undergoing Cesarean delivery for invasive placentation: A retrospective cohort study of 50 consecutive cases. Can J Anaesth. 2016;63:1233-1244.

44. Hong JY, Jee YS, Yoon HJ, Kim SM. Comparison of general and epidural anesthesia in elective cesarean section for placenta previa totalis: Maternal hemodynamics, blood loss and neonatal outcome. Int J Obstet Anesth. 2003;12:12-16.

45. Butwick AJ, Carvalho B, El-Sayed YY. Risk factors for obstetric morbidity in patients with uterine atony undergoing caesarean delivery. $\mathrm{Br}$ J Anaesth. 2014;113:661-668.

46. Walker MG, Pollard L, Talati C, et al. Obstetric and anaesthesia checklists for the management of morbidly adherent placenta. J Obstet Gynaecol Can. 2016;38:1015-1023.

47. WOMAN Trial Collaborators. Effect of early tranexamic acid administration on mortality, hysterectomy, and other morbidities in women with post-partum haemorrhage (WOMAN): An international, randomised, double-blind, placebo-controlled trial. Lancet. 2017;389: 2105-2116.

48. Simonazzi G, Bisulli M, Saccone G, Moro E, Marshall A, Berghella V. Tranexamic acid for preventing postpartum blood loss after cesarean delivery: A systematic review and meta-analysis of randomized controlled trials. Acta Obstet Gynecol Scand. 2016;95:28-37.

49. Lakshmi SD, Abraham R. Role of prophylactic tranexamic acid in reducing blood loss during elective caesarean section: A randomized controlled study. J Clin Diagn Res. 2016;10:17-21.

50. Ray I, Bhattacharya R, Chakraborty S, Bagchi C, Mukhopadhyay S. Role of Intravenous tranexamic acid on caesarean blood loss: A Prospective randomised study. J Obstet Gynaecol India. 2017;66:347-352.

51. Maged AM, Helal OM, Elsherbin MM, et al. A randomized placebocontrolled trial of preoperative tranexamic acid among women undergoing elective cesarean delivery. Int J Gynecol Obstet. 2015;131: 265-268.

52. Chou MM, Kung HF, Hwang JI, Chen WC, Tseng JJ. Temporary prophylactic intravascular balloon occlusion of the common iliac arteries before cesarean hysterectomy for controlling operative blood loss in abnormal placentation. Taiwan J Obstet Gynecol. 2015;54: 493-498.

53. Luo F, Xie L, Xie P, Liu S, Zhu Y. Intraoperative aortic balloon occlusion in patients with placenta previa and/or placenta accreta: A retrospective study. Taiwan J Obstet Gynecol. 2017;56:147-152.

54. Takahashi H, Ohkuchi A, Usui R, Suzuki H, Baba Y, Matsubara S. Factors contributing to massive blood loss on peripartum hysterectomy for abnormally invasive placenta: Who bleeds more? Obstet Gynecol Int. 2016;2016:5349063.

55. Teixidor Vinas M, Chandraharan E, Moneta MV, Belli AM. The role of interventional radiology in reducing haemorrhage and hysterectomy following caesarean section for morbidly adherent placenta. Clin Radiol. 2014;69:e345-e351.

56. Ballas J, Hull AD, Saenz C, et al. Preoperative intravascular balloon catheters and surgical outcomes in pregnancies complicated by placenta accreta: A management paradox. Am J Obstet Gynecol. 2012;207:216.e1-216.e5.

57. Cali G, Forlani F, Giambanco L, et al. Prophylactic use of intravascular balloon catheters in women with placenta accreta, increta and percreta. Eur J Obstet Gynecol Reprod Biol. 2014;179:36-41. 
58. Carnevale FC, Kondo MM, de Oliveira Sousa W Jr, et al. Perioperative temporary occlusion of the internal iliac arteries as prophylaxis in cesarean section at risk of hemorrhage in placenta accreta. Cardiovasc Intervent Radiol. 2011;34:758-764.

59. D'Souza DL, Kingdom JC, Amsalem H, Beecroft JR, Windrim RC, Kachura JR. Conservative management of invasive placenta using combined prophylactic internal iliac artery balloon occlusion and immediate postoperative uterine artery embolization. Can Assoc Radiol. 2015;66:179-184.

60. Duan XH, Wang YL, Han XW, et al. Caesarean section combined with temporary aortic balloon occlusion followed by uterine artery embolisation for the management of placenta accreta. Clin Radiol. 2015;70:932-937.

61. Kidney DD, Nguye AM, Ahdoot D, Bickmore D, Deutsch LS, Majors C. Prophylactic perioperative hypogastric artery balloon occlusion in abnormal placentation. Am J Roentgenol. 2001;176:1521-1524.

62. Dubois J, Garel L, Grignon A, Lema M, Leduc L. Placenta percreta: Balloon occlusion and embolization of the internal iliac arteries to reduce intraoperative blood losses. Am J Obstet Gynecol. 1997; 176:723-726.

63. Minas V, Gul N, Shaw E, Mwenenchanya S. Prophylactic balloon occlusion of the common iliac arteries for the management of suspected placenta accreta/percreta: Conclusions from a short case series. Arch Gynecol Obstet. 2015;291:461-465

64. Mok M, Heidemann B, Dundas K, Gillespie I, Clark V. Interventional radiology in women with suspected placenta accreta undergoing caesarean section. Int J Obstet Anesth. 2008;17:255-261.

65. Panici PB, Anceschi M, Borgia ML, et al. Intraoperative aorta balloon occlusion: Fertility preservation in patients with placenta previa accreta/increta. J Matern Fetal Neonatal Med. 2012;25:2512-2516.

66. Shih JC, Liu KL, Shyu MK. Temporary balloon occlusion of the common iliac artery: New approach to bleeding control during cesarean hysterectomy for placenta percreta. Am J Obstet Gynecol. 2005;193:1756-1758.

67. Sivan E, Spira M, Achiron R, et al. Prophylactic pelvic artery catheterization and embolization in women with placenta accreta: Can it prevent cesarean hysterectomy? Am J Perinatol. 2010;27:455-461.

68. Tan $\mathrm{CH}$, Tay KH, Sheah $\mathrm{K}$, et al. Perioperative endovascular internal iliac artery occlusion balloon placement in management of placenta accreta. Am J Roentgenol. 2007;189:1158-1163.

69. Salim R, Chulski A, Romano S, Garmi G, Rudin M, Shalev E. Precesarean prophylactic balloon catheters for suspected placenta accreta: A randomized controlled trial. Obstet Gynecol. 2015;126:1022-1028.

70. Bodner LJ, Nosher JL, Gribbin C, Siegel RL, Beale S, Scorza W. Balloon-assisted occlusion of the internal iliac arteries in patients with placenta accreta/percreta. Cardiovasc Intervent Radiol. 2006;29:354-361.

71. Shrivastava V, Nageotte M, Majo C, Haydo M, Wing D. Case-control comparison of cesarean hysterectomy with and without prophylactic placement of intravascular balloon catheters for placenta accreta. Am J Obstet Gynecol. 2007;197:402.e1-402.e5.

72. Levine AB, Kuhlman K, Bonn J. Placenta accreta: Comparison of cases managed with and without pelvic artery balloon catheters. J Matern Fetal Med. 1999;8:173-176.

73. Clausen C, Stensballe J, Albrechtse CK, Hanse MA, Lonn L, LanghoffRoos J. Balloon occlusion of the internal iliac arteries in the multidisciplinary management of placenta percreta. Acta Obstet Gynecol Scan 2013;92:386-391.

74. Sentilhes L, Goffinet F, Kayem G. Management of placenta accreta. Acta Obstet Gynecol Scand. 2013;92:1125-1134.

75. Greenberg JI, Suliman A, Iranpou P, Angle N. Prophylactic balloon occlusion of the internal iliac arteries to treat abnormal placentation: A cautionary case. Am J Obstet Gynecol. 2007;197: 470.e1-470.e4.
76. Sewell MF, Rosenblum D, Ehrenberg H. Arterial embolus during common iliac balloon catheterization at cesarean hysterectomy. Obstet Gynecol. 2006;108:746-748.

77. Teare J, Evans E, Belli A, Wendler R. Sciatic nerve ischaemia after iliac artery occlusion balloon catheter placement for placenta percreta. Int J Obstet Anesth. 2014;23:178-181.

78. Chouliaras S, Hickling DJ, Tuck JS. Thromboembolism of the leg following prophylactic balloon occlusion of the uterine arteries. BJOG. 2009;116:1278-1279.

79. Gagnon J, Boucher L, Kaufman I, Brown R, Moore A. Iliac artery rupture related to balloon insertion for placenta accreta causing maternal hemorrhage and neonatal compromise. Can J Anaesth. 2013;60:1212-1217.

80. Bishop S, Butler K, Monaghan S, Chan K, Murphy G, Edozie L. Multiple complications following the use of prophylactic internal iliac artery balloon catheterisation in a patient with placenta percreta. Int J Obstet Anesth. 2011;20:70-73.

81. Matsueda S, Hidaka N, Kondo Y, Fujiwara A, Fukushima K, Kato K. External iliac artery thrombosis after common iliac artery balloon occlusion during cesarean hysterectomy for placenta accreta in cervicoisthmic pregnancy. J Obstet Gynaecol Res. 2015;41:1826-1830.

82. Dilauro MD, Dason S, Athreya S. Prophylactic balloon occlusion of internal iliac arteries in women with placenta accreta: Literature review and analysis. Clin Radiol. 2012;67:515-520.

83. Neb H, Zacharowski K, Meybohm P. Strategies to reduce blood product utilization in obstetric practice. Curr Opin Anaesthesiol. 2017;30:294-299.

84. McDonnell NJ, Kennedy D, Long LJ, Gallagher-Swann MC, Paech MJ. The development and implementation of an obstetric cell salvage service. Anaesth Intensive Care. 2010;38:492-499.

85. Elagamy A, Abdelaziz A, Ellaithy $M$. The use of cell salvage in women undergoing cesarean hysterectomy for abnormal placentation. Int $J$ Obstet Anesth. 2013;22:289-293.

86. Lew $\mathrm{E}$, Tagore $\mathrm{S}$. Implementation of an obstetric cell salvage service in a tertiary women's hospital. Singapore Med J. 2015;56:445-449.

87. Albright CM, Rouse DJ, Werner EF. Cost savings of red cell salvage during cesarean delivery. Obstet Gynecol. 2014:124:690-696.

88. Esper SA, Waters JH. Intra-operative cell salvage: A fresh look at the indications and contraindications. Blood Transfus. 2011;9:139-147.

89. Weiniger CF, Kabiri D, Ginosar Y, Ezra Y, Shachar B, Lyell DJ. Suspected placenta accreta and cesarean hysterectomy: Observational cohort utilizing an intraoperative decision strategy. Eur J Obstet Gynecol Reprod Biol. 2016;198:56-61.

90. Belfort MA, Shamshiraz AA, Fox K. Minimizing blood loss at cesareanhysterectomy for placenta previa percreta. Am J Obstet Gynecol. 2017;216:78.e1-78.e2.

91. Rossetti D, Vitale SG, Bogani G, Rapisarda AM, Gulino FA, Frigerio L. Usefulness of vessel-sealing devices for peripartum hysterectomy: A retrospective cohort study. Updates Surg. 2015;67:301-304.

92. Arendas K, Lortie KJ, Singh SS. Delayed laparoscopic management of placenta increta. J Obstet Gynaecol Can. 2012;34:186-189.

93. Smith DD, Perez-Delboy A, Burke WM, Tergas Al. Buttock necrosis after uterine artery embolization for delayed hysterectomy in placenta percreta. Case Rep Obstet Gynecol. 2016;2016:6921280.

94. Rupley DM, Tergas AI, Palmerola KL, Burke WM. Robotically assisted delayed total laparoscopic hysterectomy for placenta percreta. Gynecol Oncol Rep. 2016;17:53-55.

95. Skinner BD, Golichowski AM, Raff GJ. Laparoscopic-assisted vaginal hysterectomy in a patient with placenta percreta. JSLS 2012;16:143-147.

96. Ochalski ME, Broach A, Lee T. Laparoscopic management of placenta percreta. J Minim Invasive Gynecol. 2010;17:128-130.

97. SelmanAE. Caesarean hysterectomy for placenta praevia/accreta using an approach via the pouch of Douglas. BJOG. 2016;123:815-819. 